\title{
PENGARUH KARAKTERISTIK INDIVIDU, PERLINDUNGAN HAK PEREMPUAN TERHADAP KUALITAS PELAYANAN KOMNAS PEREMPUAN DENGAN KOMPETENSI SUMBER DAYA MANUSIA SEBAGAI VARIABEL MEDIASI
}

\author{
Laurensius Arliman $\mathbf{S}^{1 \text { ), }}$ Isdal Veri ${ }^{2)}$, Gustiwarni ${ }^{\text {3) }}$, Elfitrayenti ${ }^{4)}$, Ade Sakurawati ${ }^{5)}$, \\ Yasri $^{6}$ \\ Magister Manejemen STIE KBP, Fakultas Ekonomi Universitas Negeri Padang \\ laurensiusarliman@gmail.com
}

\begin{abstract}
The purpose of this study was to determine the effect of individual characteristics on the quality of services in Komnas Perempuan, protection of women's rights to service quality in Komnas Perempuan, individual characteristics of human resource competencies in Komnas Perempuan, human resource competencies on service quality in Komnas Perempuan, protection of women's rights to human resource competencies in Komnas Perempuan, human resource competencies in mediating the relationship between characteristics and quality of services in Komnas Perempuan, and human resource competencies mediating the relationship between protecting women's rights and the quality of services protecting women rights in Komnas Perempuan. Based on the formulation, objectives and research hypotheses, the method used in this study is quantitative research with a descriptive approach. Descriptive approach can be interpreted as a research method that seeks. The results found that the individual characteristics variable had a significant effect on the human resource variables of the National Commission on Violence Against Women employees. The variable on the protection of women's rights has a significant effect on the human resource variable of the National Commission's female employees. Individual Characteristics Variable has a significant effect on service quality variables in the National Commission on Violence Against Women. The variable of human resources has a significant effect on the variable service quality of employees. The variable on the protection of women's rights has a significant effect on the variable service quality of employees. 6) Characteristic variable does not significantly influence Service Quality through human resource construct variables. 7) The variable for the protection of women's rights does not significantly influence the Quality of Service through the human resource construct variable.
\end{abstract}

Keywords: Human Resources, Mediation, Komnas Perempuan.

Abstrak: Tujuan penelitian ini adalah untuk mengetahui pengaruh karakteristik individu terhadap kualitas pelayanan di Komnas Perempuan, perlindungan hak perempuan terhadap kualitas pelayanan di Komnas Perempuan, karakteristik individu terhadap kompetensi sumber daya manusia di Komnas Perempuan, kompetensi sumber daya manusia terhadap kualitas pelayanan di Komnas Perempuan, perlindungan hak perempuan terhadap kompetensi sumber daya manusia di Komnas Perempuan, kompetensi sumber daya manusia dalam memediasi hubungan antara karakteristik dan kualitas pelayanan pada Komnas Perempuan, dan kompetensi sumber daya manusia memediasi hubungan antara perlindungan hak perempuan dan kualitas pelayanan perlindungan hak perempuan pada Komnas Perempuan. Berdasarkan rumusan, tujuan dan hipotesis penelitian maka metode yang digunakan dalam penelitian ini adalah penelitian kuantitatif dengan pendekatan deskriptif. Pendekatan deskriptif dapat diartikan sebagai metode penelitian yang berusaha. Hasil penelitian menemukan bahwa variabel karakteristek individu berpengaruh signifikan terhadap variabel sumber daya manusia pegawai Komnas Perempuan. Variabel perlindungan hak perempuan berpengaruh signifikan terhadap variabel sumber daya manusia pegawai komnas perempuan. Variabel Karakteristik Individu berpengaruh signifikan terhadap variabel kualitas pelayanan di Komnas Perempuan. Variabel sumber daya manusia berpengaruh signifikan terhadap variabel kualitas pelayanan pegawai. Variabel perlindungan hak perempuan berpengaruh signifikan terhadap variabel kualitas 
pelayanan pegawai. 6) Variabel karakteristik tidak berpengaruh signifikan Kualitas Pelayanan melalui variabel konstruk sumber daya manusia. 7) Variabel perlindungan hak perempuan tidak berpengaruh signifikan Kualitas Pelayanan melalui variabel konstruk sumber daya manusia.

Kata Kunci: Sumber Daya Manusia, Mediasi, Komnas Perempuan.

\section{A. PENDAHULUAN}

\subsection{Latar Belakang Masalah}

Ketidakadilan yang dialami kaum perempuan masih merupakan fenomena yang tidak kelihatan. Hal ini mendorong mereka untuk memproklamasikan serangkaian hakhak perempuan sebagai pelindturg dari berbagai bentuk kekerasan, diskriminasi dan degradasi yang tidak kelihatan tersebut. Dengan menyuarakan aspirasi mereka tentang HAM pada dasarnya kaum perempuan membawa ke garis terdepan nilai-nilai dan tuntutan akan keadilan yang bukan ekslusif perempuan, tetapi demi kelangsungan hidup manusia keseluruhan. Hak asasi perempuan sebagai HAM tampaknya masih menjadi pertanyaan dan perdebatan sampai sekarang (Seo-Young Cho, Dreher, Alex, Neumayer 2013). Mengapa perempuan sebagai bagian dari manusia harus membedakan diri dengan meminta hak-hak khusus? Ada beberapa argumen yang muncul dalam menjelaskan hal tersebut. Argumen terpenting adalah karena inherennya struktur hubungan "gender" yang bersifat asimetris di dalam diri perempuan, sebagai hasil bekerjanya sistem nilai yang pahiarhki, yaitu sistem struktural dari dominasi laki-laki baik terhadap reproduksi biologis, kontrol terhadap kerja, idiologi maupun pola hubungan sosial dari gender (Arminanto 2013).

Diskriminasi berbasis gender, termasuk sunat perempuan, hak reproduksi, kesenjangan upah dan kekerasan seksual; diperkirakan menimbulkan kerugian hingga enam triliun dolar atau berarti $0,75 \%$ ekonomi dunia. OECD menilai Swiss memiliki skor diskriminasi "sangat rendah" yaitu 8,1 dari 100, berkat undang-undang dan norma sosial yang kuat dan mengedepankan isu-isu itu, serta Kompetensi Sumber daya manusia yang aktif memperjuangkan hak-hak perempuan. Penelitian dari (Lieber 2017) menyatakan bahwa unsur-unsur sebuah organisasai perlindungan hak perempuan itu terpenuhi dilihat dari: 1) proses pengaduan dan pelaporan, 2) penanganan korban yang melapor, 3) melakukan kerjasama dengan pihak lain ataupun pihak ketiga, dan 4) sosialisasi ataupun edukasi terkait unsur-unsur perlindungan hak perempuan.

Komnas Perempuan (Perempuan 2017) merupakan penjembatan antara masyarakat dengan pemerintah. Mandat dari Komnas Perempuan adalah untuk: 1) mengembangkan kondisi yang kondusif bagi penghapusan kekerasan terhadap perempuan dan penegakan HAM, khususnya HAM Perempuan; dan 2) meningkatkan upaya pencegahan dan penanggulangan segala bentuk kekerasan terhadap perempuan dan perlindungan HAM Perempuan. Peraturan Presiden Nomor 65 tahun 2005, mengatur tugas dan lingkup kerja Komnas Perempuan. Ada 5 (lima) tugas dan lingkup kerja Komnas Perempuan, yakni: meningkatkan kesadaran publik, melakukan tinjau ulang atas produk hukum, melakukan pemantauan kasus kekerasan terhadap perempuan, menyediakan masukan dan rekomendasi, dan membangun kerjasama di tingkat lokal, nasional, regional dan internasional. Komnas Perempuan tidak diberikan tugas dan lingkup kerja untuk mendampingi korban kekerasan satu persatu. Walau demikian, tidak mungkin juga Komnas Perempuan menolak apabila ada korban kekerasan yang datang ke Komnas Perempuan. Akhirnya, sejak tahun 2005, Komnas Perempuan membangun Unit Pengaduan untuk Rujukan (UPR). Unit ini yang bertugas untuk menerima pengaduan, baik datang lansung, telepon maupun email. Setelah kasus 
didokumentasikan, korban lalu dirujuk ke lembaga mitra Komnas Perempuan yang memiliki layanan sesuai dengan kebutuhan korban.

Pengaduan kasus kekerasan terhadap perempuan pada tahun 2018 meningkat 14\% dari tahun sebelumnya. Peningkatan pengaduan ini mengindikasikan semakin meningkatnya kesadaran masyarakat untuk mengungkapkan kasus kekerasan terhadap perempuan dan semakin membaiknya mekanisme pencatatan dan pendokumentasian kasus-kasus kekerasan terhadap perempuan di lembaga-lembaga layanan. Situasi ini tidak seragam di semua wilayah, karena hingga tahun ini, 3 propinsi di Bagian Timur Indonesia yaitu Maluku Utara, Papua dan Papua Barat, masih belum memiliki data tentang kekerasan terhadap perempuan yang bisa diakses secara nasional. Seperti tahun sebelumnya, wilayah tertinggi yang mencatat angka pengaduan kekerasan terhadap perempuan, adalah Propinsi Jawa Tengah, Propinsi Jawa Timur dan DKI Jakarta. Peningkatan ini sejalan dengan intensitas upaya perbaikan akses keadilan yang telah dilakukan melalui Pengembangan Sistem Peradilan Pidana Terpadu Penanganan Kasus Kekerasan terhadap Perempuan (SPPT PKKTP), khususnya di Jawa Tengah (Komnas Perempuan 2019).

Selain hal tersebut berdasarkan dari hasil penelitian mini Penulis menemukan bahwa pegawai di Komnas Perempuan masih sangat minim hanya berjumlah 64 pegawai yang sudah mencakup dari Ketua dan para Komisioner. Mengingat banyaknya kasus pengaduan yang diadukan Pelapor ke Komnas Perempuan, masih belum diimbangi dengan jumlah pegawai dari Komnas Perempuan. Pegawai Komnas Perempuan, bukan pegawai Pegawai Negeri Sipili walaupun mereka sebagai lembaga negara yang diakui oleh pemerintah. Pegawai Komnas Perempuan disebut Badan pekerja Komnas Perempuan. Sistem perekrutan pegawai di Komnas Perempuan juga tidak mengikuti aturan PNS yang mesti lewat CPNS. Sistemnya mirip perusahaan swasta. Bila ada kebutuhan pegawai, Komnas Perempuan akan menginformasikan ke publik melalui website, atau media sosial. Para kandidat akan melalui tes tertulis dan wawancara sebelum bergabung dengan Komnas Perempuan.

Selain itu di Komnas Perempuan, ada beberapa skema kesukarelawanan. Yang pertama, relawan di Unit Pengaduan untuk Rujukan (UPR). Pendaftaran untuk relawan di unit ini dibuka setiap tahun, sekitar bulan Agustus atau September, untuk periode 1 (satu) tahun. Relawan yang terpilih akan mendapat pembekalan bagaimana menerima korban, dan pemulihan di akhir periode. Untuk bergabung dengan unit ini ada beberapa syarat, antar lain harus perempuan, dan minimal 22 tahun. Usia minimal 22 tahun, karena pengalaman Komnas Perempuan, bila petugas penerima pengaduan terlalu muda, korban enggan untuk bicara. Halini dilakukan agar kinerja Komnas Perempuan dapat berjalan dengan lebih baik lagi (Patra 2012). Karakteristik individu terhadap kualitas pelayanan perlindungan hak perempuan dan anak perempuan merupakan salah satu hal yang paling penting dalam mewujudkan Komnas Perempuan yang diiedealkan oleh setiap Perempuan dan Anak Perempuan yang haknya ingin dibela. Hasil penelitian (Affandi 2019) menyatakan kepuasan pelayanan menjadi salah satu isu penting, sehingga kepuasan pelayanan perlu dilakukan penelitian dengan mengevaluasi kinerja pelayanan individu terhadap pelanggan. Kepuasan pelapor merupakan suatu prioritas pelayanan yang harus diberikan oleh suatu lembaga untuk memperluas jangkauan pelayanan, terutama untuk masyarakat perkotaan dan pedalaman. 


\subsection{Perumusan Masalah}

Berdasarkan permasalahan yang ada, maka dikemukakan perumusan masalah sebagai berikut: apakah perlindungan hak perempuan berpengaruh signifikan terhadap kualitas pelayanan di Komnas Perempuan? apakah Kompetensi Sumber daya manusia memediasi hubungan antara karakteristik dan kualitas pelayanan pada Komnas Perempuan? apakah Kompetensi Sumber daya manusia memediasi hubungan antara perlindungan hak perempuan dan kualitas pelayanan perlindungan hak perempuan pada Komnas Perempuan?

\subsection{Tujuan Penelitian}

Adapun tujuan yang akan dicapai dalam penelitian ini adalah untuk mengetahui secara empiris: Untuk mengetahui pengaruh perlindungan hak perempuan terhadap kualitas pelayanan di Komnas Perempuan. Untuk mengetahui Kompetensi Sumber daya manusia memediasi hubungan antara karakteristik dan kualitas pelayanan pada Komnas Perempuan. Untuk mengetahui Kompetensi Sumber daya manusia memediasi hubungan antara perlindungan hak perempuan dan kualitas pelayanan perlindungan hak perempuan pada Komnas Perempuan.

\section{B. TINJAUAN PUSTAKA}

\subsection{Kompetensi Sumber Daya Manusia}

Menurut Amstrong dan Baron (Wibowo 2008) Kompetensi merupakan dimensi perilaku yang berada di belakang kinerja kompeten. Seringdinamakan kompetensi perilaku karena dimaksudkan untuk menjelaskan bagaimanaorang berperilaku ketika mereka menjalankan perannya dengan baik. Pengertian dan arti kompetensi menurut Lyle Spencer \& Signe Spencer (Moeheriono 2010)) adalah karakteristik yang mendasari seseorangberkaitan dengan efektivitas kinerja individu dalam pekerjaannya atau karakteristikdasar individu yang memiliki hubungan kausal atau sebagai sebab-akibat dengankriteria yang dijadikan acuan, efektif atau berkinerja prima atau superior di tempatkerja atau pada situasi tertentu (A competency is an underlying characteristic of anindividual that is causally related to criterian referenced effective and or superior performance in a job or situation). Berdasarkan dari definisi tersebut, maka beberapa makna yang terkandung didalamnya adalah sebagai berikut: a) Karakteristik dasar (underlying characteristic) kompetensi adalah bagian dari kepribadian yang mendalam dan melekat pada seseorang serta mempunyai perilaku yang dapat diprediksi pada berbagai keadaan tugas pekerjaan; b) Hubungan kausal (causally related) berarti kompetensi dapat menyebabkan atau digunakan untuk memprediksikan kinerja seseorang, artinya jika mempunyai kompetensi yang tinggi, maka akan mempunyai kinerja tinggi pula (sebagai akibat); dan c) Kriteria (criterian referenced) yang dijadikan sebagai acuan, bahwa kompetensi secara nyata akan memprediksikan seseorang dapat bekerjadengan baik, harus terukur dan spesifik atau terstandar.

\subsection{Karakteristik Individu}

Karakteristik individu adalah perbedaan individu dengan individu lainnya. Kompetensi Sumber daya yang terpenting dalam organisasi adalah Kompetensi Sumber daya manusia, orang-orang membarikan tenaga, bakat, kreatifitas, dan usaha mereka dalam organisasi agar suatu organisasi tetap eksistensinya. Setiap manusia memiliki karakteristik individu yang berbeda antara satu dengan yang lainnya. (Ratih Hurriyati 2005) memberikan pengertian tentang karakteristik individu sebagai berikut: 
"Karakteristik individu merupakan proses psikologi yang mempengaruhi individu dalam memperoleh, mengkonsumsi serta menerima barang dan jasa serta pengalaman. Karakteristik individu merupakan faktor internal (interpersonal) yang menggerakan dan mempengaruhi individu". Menurut (Ribhan 2008) karakteristik individu mencakup usia, jenis kelamin, tingkat pendidikan, status perkawinan di masa kerja dalam organisasi. Menurut Thoha dalam (Ribhan 2008) Karakteristik individu dapat di lihat dari: 1) Keahlian; 2) Pendidikan; dan 3) Pengalaman kerja

\subsection{Perlindungan Hak Perempuan}

Memberikan perlindungan hukum bagi perempuan, Perseriktan Bangsa-Bangsa (PBB) telah mengeluarkan Deklarasi Penghapusan Diskriminasi Terhadap Perempuan, yang memuat hak dan kewajiban berdasarkan persamaan hak dengan laki-laki. Berdasarkan deklarasi ini komisi PBB tentang Kedudukan Perempuan menyusun rancangan Konvensi tentang Penghapusan Segala Bentuk Diskriminasi Terhadap Perempuan (Convention on the Elimination of All Forms of Discrimination Against Women-CEDAW) (ILO 2017). Pada tanggal 18 Desember 1979, Majelis Umum PBB menyetujui Konvensi Penghapusan Segala Bentuk Diskriminasi Terhadap Perempuan. Perempuan berhak memperoleh perlindungan hak-hak asasi manusia. Kekerasan terhadap perempuan merupakan pelanggaran terhadap hak asasi manusia, yang dapat berupa pelanggaran terhadap: Hak atas kehidupan, Hak atas persamaan, Hak atas kemerdekaan dan keamanan pribadi, Hak atas perlindungan yang sama di muka umum, Hak untuk mendapatkan pelayanan kesehatan fisik maupun mental yang sebaikbaiknya, Hak atas pekerjaan yang layak dan kondisi kerja yang baik, Hak untuk pendidikan lanjut, Hak untuk tidak mengalami penganiayaan atau bentuk kekejaman lain, perlakuan atau penyiksaan secara tidak manusiawi yang sewenang-wenang (Stephan Kirchner 2015).

Perempuan berhak untuk menikmati dan memperoleh perlindungan hak asasi manusia dalam bidang politik, ekonomi, sosial, budaya, sipil, dan bidang-bidang lainya. Bentuk-bentuk perlindungan hukum bagi perempuan yang ada dalam khasanah Hukum Pidana Indonesia secara umum diatur dalam Kitab Undang-undang Hukum Pidana dan secara khusus diantaranya diatur dalam Undang-Undang Nomor 23 Tahun 2004 tentang Penghapusan Kekerasan Dalam Rumah Tangga dan Peraturan Pemerintah Nomor 4 Tahun 2006 tentang Penyelenggaraan dan Kerjasama Pemulihan Korban Kekerasan Dalam Rumah Tangga (Prihastuti 2016). Namun demikian masih perlu upaya-upaya untuk pelaksanaan undang-undang tersebut baik secara teknis peraturan di bawahnya maupun sarana dan prasarananya. Konstruksi Gender dalam masyarakat seringkali dianggap kewajaran dalam membuat fakta pelanggaran HAM khusus yang dialami oleh perempuan tidak terungkap (Sarwono 2014). Perempuan rentan mengalami pelanggaran HAM yang serupa berulang-ulang dan hak-haknya yang khusus terlindungi. Dalam konteks perjuangan HAM di kelompok feminis (kelompok yang memiliki kapasitas analisis keberpihakan terhadap perempuan) (Apitulay 2017).

\subsection{Kualitas Pelayanan}

Kualitas secara umum dapat diartikan sebagai kondisi dinamis yang berhubungan dengan produk, jasa, manusia, proses dan lingkungan yang memenuhi atau melebihi harapan. Menurut (Lupiyoadi 2013) kualitas adalah keseluruhan ciri dan karkateristik dari suatu produk/jasa dalam hal kemampuannya untuk memenuhi kebutuhan yang telah ditentukan atau bersifat laten. Sedangkan menurut pendapat (Christopher H Lovelock 
2011), layanan adalah kegiatan ekonomi yang ditawarkan oleh salah satu pihak kepada pihak lain. Seringkali berbasis waktu, kinerja membawa hasil yang diingkan ke penerima, benda atau asset lainnya adalah tanggung jawab pembeli. Kualitas pelayanan menjadi suatu keharusan yang harus dilakukan perusahaan supaya mampu bertahan dan tetap mendapat kepercayaan pelanggan. Menurut (Philip Kotler 2009), pelayanan adalah: "A service is any act of performance that one party can offer to another that essentially intabgible and does not result in ownership of anything is production may or may no be tied physical product". Artinya layanan adalah setiap tindakan kinerja yang salah satu pihak dapat menawarkan yang lain yang intinya intabgible dan tidak mengakibatkan kepemilikan apapun yang produksi mungkin atau mungkin tidak terikat produk fisik.

Kotler dan Keller (Philip Kotler 2009) mendefinisikan kualitas pelayanan sebagai kemampuan perasaan untuk memuaskan kebutuhan dan keinginan konsumen. Menurut Samad (2014:40) kualitas pelayanan yang dirasakan telah didasarkan pada perbedaan antara nilai yang mengharapkan pelanggan dari layanan dan apa yang dianggap kasus aktual. Kualitas layanan memiliki dampak yang besar pada beberapa hal, salah satunya adalah kepuasan pelanggan (Arliman 2017). Kepuasan pelanggan berarti perbandingan apakah pelanggan telah menerima apa yang mereka harapkan atau tidak, serta mengukur respon positif atau negatif jangka pendek pelanggan terhadap layanan yang telah diterima. Sehingga disimpulkan bahwa service quality memiliki efek positif dan signifikan pada kepuasan pelanggan (Arliman 2016b). Samad menemukan bahwa semua indikator service quality memberikan kontribusi semua dalam memuaskan pelanggan, namun indikator empaty memberikan kontribusi tersebsar dalam membentuk kepuasan pelanggan (Arliman 2016a).

\subsection{Hipotesis Penelitian}

Berdasarkan landasan teori dan kerangka konseptual yang telah dikemukakan sebelumnya, maka hipotesis yang dapat dikembangkan dalam penelitian ini adalah sebagai berikut: Perlindungan hak perempuan berpengaruh signifikan terhadap kualitas pelayanan di Komnas Perempuan. Kompetensi sumber daya manusia memediasi hubungan antara karakteristik dan kualitas pelayanan pada Komnas Perempuan. Kompetensi sumber daya manusia memediasi hubungan antara perlindungan hak perempuan dan kualitas pelayanan perlindungan hak perempuan pada Komnas Perempuan.

\section{METODE PENELITIAN}

Berdasarkan rumusan, tujuan dan hipotesis penelitian maka metode yang digunakan dalam penelitian ini adalah penelitian kuantitatif dengan pendekatan deskriptif. Pendekatan deskriptif dapat diartikan sebagai metode penelitian yang berusaha menggambarkan dan menginterpretasi objek sesuai dengan apa adanya. Penelitian ini juga menggunakan metode survei (Darmadi, 2013). Dari uraian pendapat ahli tersebut maka penelitian ini melihat karakteristik individu terhadap pengaruh karakteristik individu, perlindungan hak perempuan dan kualitas pelayanan terhadap Kompetensi Sumber daya manusia di Komnas Perempuan. Objek penelitian menurut (Suryabrata 2014) merupakan faktor-faktor yang berperanan dalam peristiwa atau gejala yang akan diteliti. Dalam penelitian ini terdapat satu variabel dependent (terikat) dan tiga variabel independent (bebas). Variabel dependent yaitu Kompetensi Sumber Daya Manusia $\left(\mathrm{Y}_{1}\right)$, dan variabel independent yaitu karakteristik individu $\left(\mathrm{X}_{1}\right)$, 
perlindungan hak perempuan $\left(\mathrm{X}_{2}\right)$, dan kualitas pelayanan $\left(\mathrm{Y}_{2}\right)$. Tehnik untuk mengumpulkan data dalam penelitian ini adalah berupa kuisioner yang disusun dengan menggunakan skala Likert. Menurut (Sugiyono 2011), skala Likert digunakan untuk mengukur sikap, pendapat, dan persepsi seseorang atau sekelompok orang tentang fenomena sosial. Dalam penelitian, fenomena sosial ini telah ditetapkan secara spesifik oleh peneliti, yang selanjutnya disebut sebagai variabel penelitian. Tehnik pengukuran yang ditetapkan adalah berdasarkan rangking atau peringkat dan atribut yang dinyatakan, dimana responden hanya memilih satu dari lima alternatif yang disediakan (Sugiyono 2011).

Data yang terkumpul melalui data primer maupun data sekunder selanjutnya dilakukan analisa dengan tujuan untuk menemukan masalah-masalah yang ada dalam Kualitas pelayanan. Dalam pengolahan data selanjutnya dalam penelitian ini digunakan statistik analitik yang dianalisis dengan bantuan Program WarpPLS Versi 5,0 untuk mengetahui lebih lanjut pengaruh antar variabel. Statistik deskriptif adalah metode statistik yang digunakan untuk menggambarkan atau mendeskripsikan data yang telah dikumpulkan menjadi sebuah informasi (Kuncoro, 2003). Penelitian ini menggunakan variabel undimensional dengan model indikator reflektif. Variabel undimensional adalah variabel yang dibentuk dari indikator-indikator baik secara reflektif maupun secara formatif (Jogiyanto dan Abdilah, 2009). Sedangkan model indikator reflektif adalah model yang mengansumsikan bahwa kovarian diantara pengukuran dijelaskan oleh varian yang merupakan manifestasi dari konstruk latennya dimana indikatornya merupakannya indikator efek (effect indikator). Menurut Ghozali (2006) Model reflektif sering disebut juga principal factor model dimana covariance pengukuran indikator dipengaruhi oleh konstruk laten. Model refleksif menghipotesiskan bahwa perubahan pada konstruk laten akan mempengaruhi perubahan pada indikator dan menghilangkan satu indikator dari model pengukuran tidak akan merubah makna atau arti konstruk (Bollen, K. 1991).

\section{HASIL PENELITIAN DAN PEMBAHASAN}

\subsection{Profil Responden}

Penelitian ini menggunakan persepsi pada Komisioner, Badan Pekerja, Relawan dan Pemagang sebagai responden penelitian. Berdasarkan 51 kuesioner yang telah dijawab dan dikembalikan oleh responden, maka profil responden dapat dilihat pada Tabel 4.1. Tabel 4.1 menunjukkan, berdasarkan jenis kelamin terlihat bahwa mayoritas responden berjenis kelamin laki-laki yaitu sebanyak 35 orang $(68,6 \%)$. Berdasarkan kategori pendidikan, dimana berdasarkan kategori ini ditemukan bahwa kebanyakan responden berpendidikan S1 sebanyak 36 orang (70,6\%). Berdasarkan usia, mayoritas responden penelitian berusia antara 25-35 tahun yaitu sebanyak 30 orang. Kategori berikutnya dibedakan berdasarkan lama kerja, mayoritas responden penelitian ini adalah mereka yang memiliki masa kerja di antara 5-9 tahun sebanyak 20 orang $(39,2 \%)$. Kategori selanjutnya adalah berdasarkan penghasilan/bulan dimana mayoritas responden berpenghasilan antara $\mathrm{Rp} 4.500 .000$ - Rp 5.499.999 sebanyak 28 orang $(54,9 \%)$. Berdasarkan status pegawai umumnya responden berada pada Badan Pekerja sebanyak 25 orang (49\%).

Tabel 4.1 Profil Responden Penelitian $(n=51)$

\begin{tabular}{|c|l|c|c|}
\hline \multirow{2}{*}{ Keterangan } & \multicolumn{1}{|c|}{ Kategori } & $\begin{array}{c}\text { Jumlah } \\
\text { (orang) }\end{array}$ & Persentase (\%) \\
\hline \multirow{2}{*}{ Jenis Kelamin } & Laki-laki & 35 & 68.6 \\
\cline { 2 - 4 } & Perempuan & 16 & 31.4 \\
\hline
\end{tabular}




\begin{tabular}{|c|c|c|c|}
\hline \multirow{4}{*}{ Pendidikan } & SMA & 5 & 9.8 \\
\hline & $\mathrm{S} 1$ & 36 & 70.6 \\
\hline & $\mathrm{S} 2$ & 6 & 11.8 \\
\hline & S3 & 4 & 7.8 \\
\hline \multirow{4}{*}{ Usia } & $<25$ tahun & 1 & 2.0 \\
\hline & 25 - 35 tahun & 30 & 58.8 \\
\hline & $36-45$ tahun & 19 & 37.3 \\
\hline & 45-55 tahun & 1 & 2.0 \\
\hline \multirow{5}{*}{ Lama Kerja } & $<5$ tahun & 12 & 23.5 \\
\hline & 5-9 tahun & 20 & 39.2 \\
\hline & 10-14 tahun & 15 & 29.4 \\
\hline & 15-19 tahun & 3 & 5.9 \\
\hline & $>20$ tahun & 1 & 2.0 \\
\hline \multirow{5}{*}{$\begin{array}{c}\text { Penghasilan / } \\
\text { bulan }\end{array}$} & $\leq \mathrm{Rp} 3.499 .000$ & 0 & 0 \\
\hline & Rp 3.500.000 - Rp 4.499.000 & 6 & 11.8 \\
\hline & $\operatorname{Rp} 4.500 .000-\operatorname{Rp} 5.499 .999$ & 28 & 54.9 \\
\hline & Rp 6.000.000 - Rp 6.499.999 & 14 & 27.5 \\
\hline & $\geq$ Rp. 7.000 .000 & 3 & 5.9 \\
\hline \multirow{4}{*}{ Status Pegawai } & Komisioner & 9 & 17,6 \\
\hline & Badan Pekerja & 25 & 49 \\
\hline & Relawan & 15 & 29,4 \\
\hline & Pemagang & 2 & 4 \\
\hline
\end{tabular}

\subsection{Uji Asumsi Klasik}

Uji asumsi klasik adalah persyaratan statistik yang harus dipenuhi pada analisis regresi linear berganda yang berbasis ordinary least square (OLS). Jadi analisis regresi yang tidak berdasarkan OLS tidak memerlukan persyaratan asumsi klasik, misalnya regresi logistik atau regresi ordinal. Demikian juga tidak semua uji asumsi klasik harus dilakukan pada analisis regresi linear, misalnya uji multikolinearitas tidak dilakukan pada analisis regresi linear sederhana dan uji autokorelasi tidak perlu diterapkan pada data cross sectional. Uji asumsi klasik juga tidak perlu dilakukan untuk analisis regresi linear yang bertujuan untuk menghitung nilai pada variabel tertentu. Pada penelitian Partial Last Square (PLS) Uji Asumsi Klasik diperlukan untuk melihat bahwa data yang ada memang layak dan cocok untuk digunakan dalam penelitian. Hasil Uji Asumsi klasik pada penelitian ini sebagai berikut:Average path coefficient $(\mathrm{APC})=0.308, \mathrm{P}=0.004$.

Dari hal ini dapat dijelaskan bahwa Average coefficient atau Koefisien rata-rata (APC) adalah sama dengan 0.308 dan P adalah sama dengan 0.004. Dengan demikian dapat disimpulkan bahwa data dalam penelitian ini memiliki kecocokan atau kesesuaian model (fit indices). Penambahan pada Average path coefficient (APC) akan menurunkan Average $R$-squared (ARS). APC dan ARS akan naik bersamaan apabila variabel laten meningkatkan kualitas penjelasan dan prediksi keseluruhan. Average adjusted $R$ squared (AARS) cenderung lebih rendah dari ARS. Unutk memenuhi syarat kecocokan model P-Value APC, ARS dan AARS harus lebih rendah dari 0,05, atau minimum APC dan ARS harus dibawah 0,05 dengan demikan model penelitian dapat diterima.

Average R-squared $(\mathbf{A R S})=\mathbf{0 . 5 6 6}, \mathbf{P}<0.001$ Dari hal ini dapat dijelaskan bahwa Average $R$-squared atau Rata-rata R-kuadrat (ARS) adalah sama dengan 0.566, $\mathrm{P}$ kurang dari 0.001 sebagai syaratnya. R-squared (reliabilitas indikator) untuk konstruk dependen dan nilai $t$-statistic dari pengujian koefisien jalur (path coefficient). Semakin tinggi nilai $r$-square berarti semakin baik model prediksi dari model penelitian yang diajukan. Nilai path coefficients menunjukkan tingkat signifikansi dalam pengujian 
hipotesis. Analisis Variant $\left(\mathrm{R}^{2}\right)$ atau Uji Determinasi berfungsi untuk mengetahui besar pengaruh variabel independen terhadap variabel dependen tersebut. Nilai $R=0.566$ menunjukkan bahwa bahwa variabel konstruk Karakteristik Individu $\left(\mathrm{X}_{1}\right)$, Perlindungan Hak Perempuan $\left(\mathrm{X}_{2}\right)$ dan Kompetensi Sumber Daya Manusia $\left(\mathrm{Y}_{1}\right)$ mampu menjelaskan variabel konstruk Kualitas Pelayanan $\left(\mathrm{Y}_{2}\right)$ sebesar $56.6 \%$, atau dengan kata lain besarnya pengaruh variabel konstruk Karakteristik Individu $\left(\mathrm{X}_{1}\right)$, Perlindungan Hak Perempuan $\left(\mathrm{X}_{2}\right)$ dan Kompetensi Sumber Daya Manusia $\left(\mathrm{Y}_{1}\right)$ terhadap variabel konstruk Kualitas Pelayanan $\left(\mathrm{Y}_{2}\right)$ adalah sebesar 56\%. Sisanya sebesar 43,4\% diterangkan oleh variabel konstruk lainnya yang tidak termasuk dalam penelitian ini.

Average adjusted $R$-squared $(\mathbf{A A R S})=\mathbf{0 . 5 4 8 ,}, \mathbf{P}<\mathbf{0 . 0 0 1}$ Sejalan dengan $R$ Squared, Adjusted $R$-Squared menunjukkan bahwa bahwa variabel konstruk Karakteristik Individu $\left(\mathrm{X}_{1}\right)$, Perlindungan Hak Perempuan $\left(\mathrm{X}_{2}\right)$ dan Kompetensi Sumber Daya Manusia $\left(\mathrm{Y}_{1}\right)$ mampu menjelaskan variabel konstruk Kualitas Pelayanan $\left(\mathrm{Y}_{2}\right)$ sebesar $54.8 \%$, atau dengan kata lain besarnya pengaruh variabel konstruk Karakteristik Individu $\left(\mathrm{X}_{1}\right)$, Perlindungan Hak Perempuan $\left(\mathrm{X}_{2}\right)$ dan Kompetensi Sumber Daya Manusia $\left(\mathrm{Y}_{1}\right)$ terhadap variabel konstruk Kualitas Pelayanan $\left(\mathrm{Y}_{2}\right)$ adalah sebesar 54.8\%. Sisanya sebesar 45,2\% diterangkan oleh variabel konstruk lainnya yang tidak termasuk dalam penelitian ini. Dari hal ini dapat dijelaskan bahwa Average adjusted $R$-squared atau Rata-rata R-squared yang disesuaikan (AARS) adalah sama dengan 0.548 , P kurang dari 0.001 sebagai syaratnya. Namun APC dan ARS telah memenuhi syarat kesesuaian model dengan demikian model tetap dianggap memenuhi syarat.

Average block VIF (AVIF) $=1.040$, acceptable if $<=5$, ideally $<=3.3$. Average block VIF (AVIF) dan Average full collinearity VIF (AFVIF) berkaitan dengan multikolinearitas. AVIF dan AFVIF yang tinggi menunjukkan variabel laten yang dilibatkan memiliki konstruk yang sama. AVIF mendeteksi kolinearitas pada hubungan linear, sebaliknya AFVIF mendeteksi kolinearitas pada hubungan non-linear. AVIF dan AFVIF harus kurang dari atau sama dengan $\leq 3.3$ bila sifat variabel laten. Bila variabel hanya memiliki satu indicator maka nilanya harus sama atau lebih dari 5. Dari hasil warpPLS dapat dijelaskan bahwa Average block VIF atau Rata-rata blok VIF (AVIF) adalah sama dengan 1.040 dapat diterima, karena dapat diterima kurang dari 5, idealnya adalah kurang dari 3.3. hal ini menunjukkan bahwa model PLS menunjukkan keseuaian dengan data.

Average full collinearity VIF $(\mathrm{AFVIF})=\mathbf{2 8 . 4 1 7}$, acceptable if $<=\mathbf{5}$, ideally $<=$ 3.3 Dari warpPLS dapat dijelaskan bahwa Average full collinearity VIF atau VIF collinearity penuh rata-rata (AFVIF) adalah sama dengan 28.417 , diterima jika kurang dari 5, sedangkan idealnya adalah 3.3. Angka ini menunjukkan bahwa model penelitian terjangkit peyakit Multikolinearitas. Namun angka AVIF yang masih dibawah 5 atau kurang dari 5, dengan demikian model dapat dikatakan fit atau menunjukkan keseuaian dengan data.

Tenenhaus GoF $($ GoF $)=0.441$, small $\geq 0.1$, medium $\geq 0.25$, large $\geq 0.36$ Fungsi dari Tenenhaus GoF (GoF) hamper sama dengan ARS, yaitu untuk mengukur kekuatan penjelasan dari model. Dengan ketetapan: 1) Kekuatan penjelasan sempit apabila GoF $\geq 0.1$; 2) Kekuatan penjelasan sedang apabila $\geq 0.25$; 3) Kekuatan penjelasan luas apabila $\geq 0.36$ Dari warpPLS dapat dijelaskan bahwa Tenenhaus GoF (GoF) adalah sama dengan 0.441. Artinya, kekuatan penjelasan variabel pada model penelitian ini sangat luas. 
Sympson's paradox ratio $(\mathrm{SPR})=\mathbf{1 . 0 0 0}$, acceptable if $>=0.7$, ideally $=1$. Model penelitian harus bebas dari Sympson's Paradox Ratio. Paradox akan terjadi apabila sebuah koefisien jalur dan sebuah korelasi terkait sepasang variabel memiliki tanda yang berbeda. Sympson's Paradox instance adalah indikasi masalah kausalitas, hipotesis jalur tidak masuk akal atau kebalikannya. Jika Sympson's Paradox Ratio $\geq 0.70$ atau lebih dari 70\% maka model dinyatakan bebas dari Sympson's Paradox instance. Dari data WarpPLS dapat dijelaskan bahwa Sympson's paradox ratio atau Rasio paradoks Sympson (SPR) adalah sama dengan 1.000, diterima jika besar sama dengan 0.7 , idealnya sama dengan 1 . Dengan demikian model peneltian ini dapat dikatakan bebas dari Sympson's Paradox instance atau dengan kata lain layak/cocok.

R-squared contribution ratio $($ RSCR $)=1.000$, acceptable if $>=0.9$, ideally $=1$. $R$-squared contribution ratio (RSCR) berfungsi untuk mengukur seberapa jauh model bebas dari $R$-Squared Contribution yang negatif. Ketika terdapat -Squared Contribution yang negative pada variabel laten terhadap variabel kriteria, menunjukkan bahwa variabel prediktor mengurangi kemampuan menjelaskan dari variabel kriteria. $R$ squared contribution ratio (RSCR) pada hasil pengolahan waroPLS menunjukkan angka sama dengan 1.000 diterima jika besar sama dengan 0.9 , idealnya sama dengan 1 . Artinya, pada model penelitian ini variabel prediktor memiliki kemampuan menjelaskan variabel kriteria dengan sangat baik.

Statistical suppression ratio $(\mathrm{SSR})=\mathbf{1 . 0 0 0}$, acceptable if $>=\mathbf{0 . 7}$. Sebuah model penelitian harus bebas dari suppression instances. Supression adalah kondisi ketika koefisien jalur dalam istilah absolut lebih besar dari korelasi yang terkait dengan sepasang variabel yang terhubung. Hubungan tidak masuk akal atau sebaliknya. Dari WarpPLS dapat dijelaskan bahwa Statistical suppression ratio atau Rasio penekanan statistik (SSR) sama dengan 1.000, diterima jika besar sama dengan 0.7. dengan demikian model dalam penelitian dinyatakan terbebas dari suppression instances.

Nonlinear bivariate causality direction ratio $(\mathrm{NLBCDR})=0.800$, acceptable if $>=0.7$. Nonlinear bivariate causality direction ratio (NLBCDR) menjelaskan seberapa jauh koefisien dua variabel non linear mendukung arah hipotesis dari model pengaruh. Outer model selain diukur dengan menilai convergent validity dan discriminant validity juga dapat dilakukan dengan melihat reliabilitas konstrak atau variabel laten yang diukur dengan nilai composite reliability, AVE dan Cronbach's Alpha. Konstruk dinyatakan reliabel jika composite reliability mempunyai nilai $>0.7$ dan Cronbach's Alpha memiliki nilai >0,6, maka konstrak dinyatakan reliabel. Jaya dan Sumerta Jaya (2008) merekomendasikan nilai akar dari AVE harus lebih besar dari 0,05. Hal ini juga didukung oleh Mohamed dan Karim (2012) yang menyatakan nilai akar kuadrat dari AVE harus diatas 0,6 cukup untuk mendukung nilai dconvergent reliability.

Nonlinear bivariate causality direction ratio atau Rasio arah kausalitas bivariat nonlinear (NLBCDR) sama dengan 0.800, diterima jika besar sama dengan 0.7 Sedangkan untuk Koefisien reliabilitas komposit, Koefisien alpha Cronbach, Varians rata-rata diekstraksi, dan VIF collinearity penuh adalah sebagai berikut ini:

Composite reliability coefficients

\begin{tabular}{|c|c|c|c|}
\hline X1 & $\mathbf{X} 2$ & Y1 & Y2 \\
\hline 0.868 & 0.870 & 0.887 & 0.878 \\
\hline \multicolumn{4}{|c|}{ Cronbach's alpha coefficients } \\
\hline X1 & $\mathbf{X} 2$ & Y1 & Y2 \\
\hline
\end{tabular}


$\begin{array}{llll}0.833 & 0.837 & 0.863 & 0.851\end{array}$

Average variances extracted

$\begin{array}{llll}\text { X1 } & \text { X2 } & \text { Y1 } & \text { Y2 } \\ \text { 0.378 } & \text { 0.330 } & \text { 0.348 } & 0.317 \\ \text { Full collinearity } & \text { VIFs }\end{array}$

$\begin{array}{llll}\mathrm{X} 1 & \mathrm{X} 2 & \mathrm{Y} 1 & \mathrm{Y} 2\end{array}$

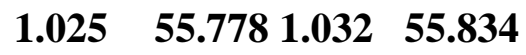

Dari tabel diatas dapat dijelaskan bahwa indikator-indikator pembentuk variable yang di teliti memang mengkonstruksikan variable tersebut atau kalimat bebasnya adalah: Dari 2 (dua) indikator pembentuk Karakteristik $\left(\mathrm{X}_{1}\right)$ memang bisa digunakan untuk mengukur Karakteristik $\left(\mathrm{X}_{1}\right)$. Begitu juga dengan hak perempuan $\left(\mathrm{X}_{2}\right)$ bisa digunakan. Terkait Average variances extracted hasilnya adalah 0.317 atau kurang dari 0.5 , maka dinyakan aman. Nilai AVE < 0,5 yang menunjukkan konstruk tidak reliabel. Namun nilai composite reliability untuk semua konstrak berada diatas nilai 0,70 dan demikian juga dengan nilai Chronbach's Alpha memiliki nilai > 0,6. Dengan nilai yang dihasilkan tersebut, menunjukkan semua indikator pembentuk variabel yang diteliti memang mengkonstruk variabel yang diteliti. Dengan kata lain dua indikator pembentuk X1 dapat digunakan unutk mrmbrntuk $\mathrm{X}_{1}$, demikian juga dengan variabel lainnya. Dapat disimpulkan bahwa semua variabel konstruk memiliki reliabilitas yang baik sesuai dengan batas nilai minumun yang telah disyaratkan.

\subsection{Hasil dan Pembahasan}

Berdasarkan hasil penelitian bisa dapat disimpulkan besarnya pengaruh tidak langsung Karakteristik $\left(\mathrm{X}_{1}\right)$ terhadap Kualitas Pelayanan $\left(\mathrm{Y}_{2}\right)$ melalui Kompetensi Sumber Daya Manusia $\left(\mathrm{Y}_{1}\right)$ adalah $0.7 \%$ / 7\%. Dari hasil penelitian juga dapat dijelaskan bahwa Perlindungan Hak Perempuan $\left(\mathrm{X}_{2}\right)$ memiliki pengaruh tidak langsung terhadap Kualitas Pelayanan $\left(\mathrm{Y}_{2}\right)$ melalui Kompetensi Sumber Daya Manusia $\left(\mathrm{Y}_{1}\right)$ adalah $0.6 \%$. Maka besarnya pengaruh tidak langsung Kualitas Pelayanan $\left(\mathrm{Y}_{2}\right)$ melalui Kompetensi Sumber Daya Manusia $\left(\mathrm{Y}_{1}\right)$ adalah $0.6 \%$ / 6\%. Dengan demikian dapat disimpulkan hipotesis Keenam $\left(\mathrm{H}_{6}\right)$ penelitian ini bahwa secara tidak langsung variabel Karakteristik $\left(\mathrm{X}_{1}\right)$ tidak berpengaruh signifikan Kualitas Pelayanan $\left(\mathrm{Y}_{2}\right)$ melalui variabel konstruk Kompetensi Sumber daya manusia $\left(\mathrm{Y}_{1}\right)$. Berdasarkan hasil penelitian bisa dapat disimpulkan bahwa Karakteristik $\left(\mathrm{X}_{1}\right)$ apakah berpengaruh apa tidak terhadap Kualitas Pelayanan $\left(\mathrm{Y}_{2}\right)$ secara tidak langsung melalui Kompetensi Sumber Daya Manusia $\left(\mathrm{Y}_{1}\right)$ besarnya adalah $47.2 \%$ (lebih dari 5\%). Maknanya adalah secara tidak langsung Karakteristik $\left(\mathrm{X}_{1}\right)$ tidak berpengaruh terhadap Kualitas Pelayanan $\left(\mathrm{Y}_{2}\right)$ melalui Kompetensi Sumber Daya Manusia ( $\left.\mathrm{Y}_{1}\right)$. Secara tidak langsung Perlindungan hak perempuan $\left(\mathrm{X}_{2}\right)$ tidak berpengaruh terhadap Kualitas Pelayanan $\left(\mathrm{Y}_{2}\right)$ melalui Kompetensi Sumber Daya Manusia ( $\mathrm{Y}_{1}$ ) karena lebih dari $47.7 \%$ (lebih dari 5\%). Dengan demikian dapat disimpulkan bahwa secara tidak langsung variabel perlindungan hak perempuan $\left(\mathrm{X}_{2}\right)$ tidak berpengaruh signifikan Kualitas Pelayanan $\left(\mathrm{Y}_{2}\right)$ melalui variabel konstruk Kompetensi Sumber daya manusia ( $\left.\mathrm{Y}_{1}\right)$. 


\section{E. PENUTUP}

Berdasarkan analisa data dan interpretasi yang telah disampaikan pada bab sebelumnya, maka dapat dikemukakan beberapa kesimpulan dari hasil penelitian ini sebagai berikut: Variabel Perlindungan Hak Perempuan $\left(\mathrm{X}_{2}\right)$ Berpengaruh Signifikan terhadap Variabel Kualitas Pelayanan Pegawai $\left(\mathrm{Y}_{2}\right)$. Variabel Karakteristik $\left(\mathrm{X}_{1}\right)$ tidak berpengaruh signifikan Kualitas Pelayanan $\left(\mathrm{Y}_{2}\right)$ melalui variabel konstruk Kompetensi Sumber daya manusia $\left(\mathrm{Y}_{1}\right)$. Variabel perlindungan hak perempuan $\left(\mathrm{X}_{2}\right)$ tidak berpengaruh signifikan Kualitas Pelayanan $\left(\mathrm{Y}_{2}\right)$ melalui variabel konstruk Kompetensi Sumber daya manusia $\left(\mathrm{Y}_{1}\right)$.

Saran praktis dari hasil penelitian ini bahwa segi pelayanan terkait pegawai belum bekerja dengan bersungguh-sungguh untuk meningkatkan kinerja dengan teknologi dan peralatan yang disediakan. Untuk itu diharapkan pimpinan komisioner memberikan masukan ke pusat agar mendapatkan alat teknologi baru yang mendukung pekerjaa, serta memberikan Pendidikan dan pelatihan bagi pegawai, pemagan dan sukarelawan dalam menggunakan teknologi baru.

\section{F. DAFTAR PUSTAKA}

Affandi, Herri. 2019. "Pengaruh Kualitas Pelayanan Terhadap Kepuasan Pelanggan Pada Perusahaan Daerah Air Minum (PDAM) Tirta Mon Pase Kabupaten Aceh Utara.” Jurnal Teknik Sipil 6(3).

Apitulay, Silvana Ranti. 2017. Analisis Kerangka HAM Berspektif Gender. Jakarta: Bidang Marturia-PGI.

Arliman, Laurensius. 2016a. "Dispensasi Perkawinan Bagi Anak Di Bawah Umur Di Pengadilan Agama Padangsidempuan." Jurnal Al Adalah 12(4).

Arliman, Laurensius. 2016b. "Kedudukan Komisi Perlindungan Anak Indonesia Sebagai State Auxiliary Bodies Dalam Sistem Hukum Ketatanegaraan Indonesia." Justitia 32(2).

Arliman, Laurensius. 2017. "Komnas HAM Sebagai State Auxiliary Bodies Di Dalam Penegakan Hak Asasi Manusia Di Indonesia.” Jendela Hukum dan Keadilan 4(1).

Arminanto, Satya. 2013. Pusat Studi Hukum Tata Negara Fakultas Hukum Universitas Indonesia Hak Asasi Manusia Dalam Transisi Politik Di Indonesia. Jakarta.

Bollen, K., Lennox R. 1991. "Conventional Wisdom on Measurement: A Structural Equation Perspective.” Psychological Bulletin 110(2): 305-314.

Christopher H Lovelock, Lauren K. Wright. 2011. Manajemen Pemasaran Jasa. II. Jakarta: Indeks.

ILO. 2017. Global Estimates of Modern Slavery: Forced Labor and Forced Marriage. Switzerland: International Labor Office.

Komnas Perempuan. 2019. Hentikan Impunitas Pelaku Kekerasan Seksual Dan Wujudkan Pemulihan Yang Komprehensif Bagi Korban. Jakarta: Komnas Perempuan.

Lieber, Marylène. 2017. "From Territories to City Centers'. The Ambivalent Management of Women's Safety and Gentrification?" French Politics 16(1).

Lupiyoadi, Rambat. 2013. Manajemen Pemasaran Jasa. Jakarta: Salemba Empat.

Moeheriono. 2010. Pengukuran Kinerja Berbasis Kompetensi. Surabaya.

Patra, Rommy. 2012. "Efektifitas Kelembagaan Komnas Perempuan Dalam Perlindungan Ham Bagi Perempuan Di Indonesia.” Jurnal Masalah-Masalah Hukum 41(4).

Perempuan, Komnas. 2017. Sejarah Panjang Komisi Nasional Anti Kekerasan 
Terhadap Perempuan. Jakarta: Komnas Perempuan.

Philip Kotler, Kevin L Keller. 2009. Manajemen Pemasaran. 1st ed. Jakarta: Erlangga.

Prihastuti, Handini. 2016. "Perlindungan Hukum Terhadap Perempuan Korban

Kekerasan Dalam Rumah Tangga (Studi Kasus Ham Solo)." Jurnal Hukum Universitas Muhammadiyah Surakarta.

Ratih Hurriyati. 2005. Bauran Pemasaran Dan Loyalitas Konsumen. Bandung: Alfabeta.

Ribhan. 2008. "Hubungan Karakteristik Individu Dengan Kinerja Karyawan Melalui Komitmen Organisasi Sebagai Variabel Mediasi (Studi Kasus Oada PT Chandra Superstore Tanjung Karang Bandar Lampung)." Jurnal Bisnis Dan Manajemen $4(2)$.

Sarwono, Billy. 2014. "Pemaknaan Karir Politik Presiden Perempuan Dalam Masyarakat Patriarki (Analisis Pemaknaan Ibu Rumah Tangga Kelas Menengah Di Jabodetabek Tentang Megawati Soekarnoputri),." Universitas Indonesia.

Seo-Young Cho, Dreher, Alex, Neumayer, Eric. 2013. "Does Legalized Prostitution Increase Human Trafficking,." Journal World Dev 41(2).

Stephan Kirchner, Vanessa Frese. 2015. "Slavery under the European Convention on Human Rights and the Jus Cogens Prohibition of Human Trafficking." Journal Human Rights 27(1).

Sugiyono. 2011. Metode Penelitian Kuantitatif, Kualitatif Dan R\&D. Bandung: Alfabeta.

Suryabrata, Sumadi. 2014. Metodologi Penelitian. 25th ed. Jakarta: Rajagrafindo Persada.

Wibowo. 2008. Manajemen Kinerja. Yogyakarta: Pustaka Pelajar. 